\title{
Pathophysiology of Resistant Hypertension: The Role of Sympathetic Nervous System
}

\author{
Costas Tsioufis, Athanasios Kordalis, Dimitris Flessas, Ioannis Anastasopoulos, Dimitris \\ Tsiachris, Vasilios Papademetriou, and Christodoulos Stefanadis
}

First Cardiology Clinic, University of Athens, Hippokration Hospital, 3 Kolokotroni Street, P. Penteli, Athens 15236, Greece

Correspondence should be addressed to Costas Tsioufis, ktsioufis@gmail.com

Received 4 October 2010; Accepted 22 December 2010

Academic Editor: Alan Gradman

Copyright (C) 2011 Costas Tsioufis et al. This is an open access article distributed under the Creative Commons Attribution License, which permits unrestricted use, distribution, and reproduction in any medium, provided the original work is properly cited.

\begin{abstract}
Resistant hypertension (RH) is a powerful risk factor for cardiovascular morbidity and mortality. Among the characteristics of patients with $\mathrm{RH}$, obesity, obstructive sleep apnea, and aldosterone excess are covering a great area of the mosaic of $\mathrm{RH}$ phenotype. Increased sympathetic nervous system (SNS) activity is present in all these underlying conditions, supporting its crucial role in the pathophysiology of antihypertensive treatment resistance. Current clinical and experimental knowledge points towards an impact of several factors on SNS activation, namely, insulin resistance, adipokines, endothelial dysfunction, cyclic intermittent hypoxaemia, aldosterone effects on central nervous system, chemoreceptors, and baroreceptors dysregulation. The further investigation and understanding of the mechanisms leading to SNS activation could reveal novel therapeutic targets and expand our treatment options in the challenging management of $\mathrm{RH}$.
\end{abstract}

\section{Introduction}

A number of physiological mechanisms are involved in the maintenance of normal blood pressure (BP), and their derangement may play a key role in the development of hypertension (HTN). Amongst other factors, unfavorable genetic substrate, activated sympathetic nervous system (SNS) and renin-angiotensin system, excess sodium intake and disturbances between vasoconstrictors and vasodilators have been implicated in the pathophysiology of HTN [1]. Although the role of the above factors in the pathogenesis of essential HTN is well established, their involvement in mechanisms responsible for treatment resistance is not so thoroughly investigated.

According to World Health Report 2002, suboptimal $\mathrm{BP}$ control is the most common attributable risk for death worldwide, being responsible for $62 \%$ of cerebrovascular disease and $49 \%$ of ischemic heart disease [2, 3]. Since resistance to treatment is one of the reasons for uncontrolled $\mathrm{BP}$, it is obvious that resistant hypertension (RH) entails a major clinical and social impact. Consequently, understanding of the mechanisms involved in the pathophysiology of treatment resistance is crucial for the development of more effective therapeutic strategies. In the present paper, we will focus on the role of SNS in the pathophysiology of RH.

\section{SNS and Patterns of Hypertension}

The development of novel and sophisticated techniques for the direct and indirect assessment of adrenergic activity has changed our conception about the role of SNS in the regulation of BP, from a short-term regulator to a cornerstone of the pathogenesis and pathophysiology of HTN. Nowadays, the established theory is that SNS hyperactivity contributes to initiation, maintenance and progression of HTN. Several studies have correlated adrenergic hyperactivity with multiple patterns of HTN. More specifically, increased SNS activity has been documented in systole-diastolic and isolated systolic HTN $[4,5]$, in white coat and masked HTN $[4,6]$, in dipping, extreme dipping, nondipping and reverse dipping conditions $[4,7]$ and in pregnancy-induced HTN $[4,8]$. Furthermore, SNS activity increases progressively and in parallel with HTN stages. This implies that the more 
advanced the stage of HTN the greater is the adrenergic activity $[4,9,10]$. Whether this correlation could be extended to $\mathrm{RH}$ remains unclear given that the SNS activity in resistant hypertensives has been assessed in subgroups of populations of intervention studies without comparison with healthy controls.

\section{The "Phenotype" of Resistant Hypertension}

According to the AHA scientific statement for RH [11], based on the demographic data and the results of Framingham and ALLHAT studies, the strongest predictors of lack of BP control were older age, high baseline BP, obesity, excessive dietary salt ingestion and chronic kidney disease. Aging and its interface with SNS activation is well documented. A number of studies have shown that whole body sympathetic neural activity increases with aging [12-16] and indices of sympathetic activity, especially muscle sympathetic nerve activity (MSNA), become more linked to BP with older age $[12,17]$.

Beyond ageing, obesity, aldosterone excess and obstructive sleep apnea (OSA) are covering a great area of the mosaic of the characteristics of resistant hypertensives. In cohorts of patients with $\mathrm{RH}$, the mean body mass index (BMI) was over $32 \mathrm{~kg} / \mathrm{m}^{2}$ and the prevalence of hyperaldosteronism was approximately $20 \%$ while the resistant hypertensives had a very high prevalence of known and suspected OSA [18-20]. Moreover, among subjects with $\mathrm{RH}$, hyperaldosteronism was more likely to be present in patients with confirmed OSA than in those at low risk for OSA. The existing data support that OSA, aldosterone excess and obesity are not only common comorbidities in resistant hypertensives but that they also interact in this setting. Although the mechanisms that link these conditions in RH are not fully elucidated, SNS activation may be a major contributing factor (Figure 1).

\section{The Interplay of SNS Activation and Resistant Hypertension}

4.1. Obesity. Obesity is associated with more severe HTN, a need for an increased number of medications and a decreased likelihood of achieving BP control [11]. The Framingham study showed that subjects with BMI $\geq$ $30 \mathrm{~kg} / \mathrm{m}^{2}$ had 1.5 -fold increased risk for uncontrolled systolic $\mathrm{BP}$ versus subjects with $\mathrm{BMI}<25 \mathrm{~kg} / \mathrm{m}^{2}[21]$. In addition, the HYDRA study, a cross-sectional study of 45,125 unselected consecutive primary care attendees conducted in Germany, showed that BP levels were consistently higher in obese patients and the odds ratios for BP control in diagnosed and treated patients were $0.8,0.6,0.5$ and 0.7 for overweight and grade 1, 2, and 3 obese patients, respectively, compared to those with normal weight [22]. Among the mechanisms involved in obesity-induced hypertension, apart from impaired sodium excretion, fluid retention and activation of the renin-angiotensin-aldosterone system, the "neuroadrenergic hypothesis" should be taken into consideration.

Before the application of more specific methodology for the estimation of SNS activity, including the direct

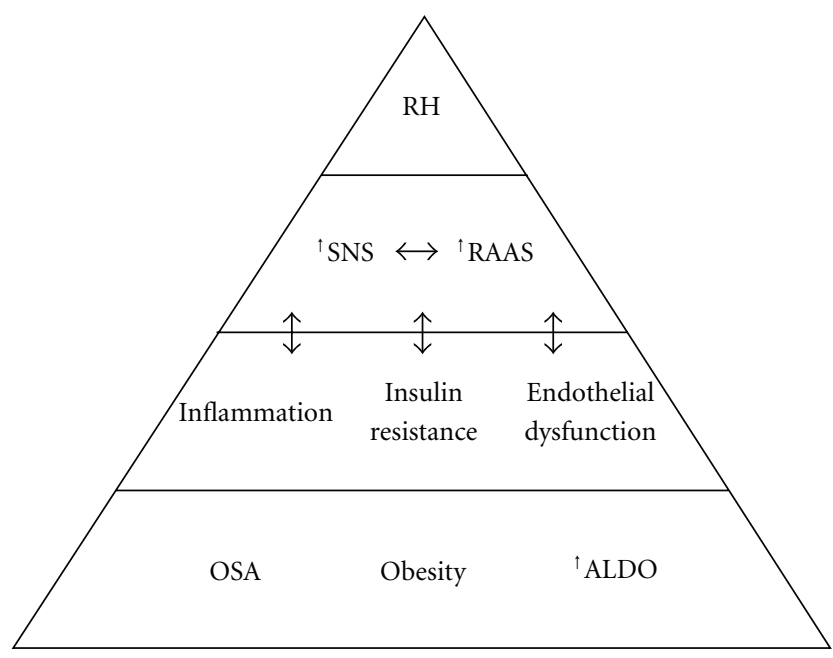

FIGURE 1: A proposed pathophysiologic pathway for the activation of SNS and the development of RH. Obesity, OSA and aldosterone excess are covering a great area of the mosaic of the phenotype of $\mathrm{RH}$ and are correlated with increased SNS activity, via multiple mechanisms. ${ }^{\dagger}$ ALDO: Aldosterone excess, OSA: Obstructive sleep apnea, ${ }^{\dagger}$ RAAS: Renin-Angiotensin-Aldosterone System activation, $\mathrm{RH}$ : Resistant hypertension, ${ }^{\dagger} \mathrm{SNS}$ : Sympathetic nervous system hyperactivity.

recordings of sympathetic nerve firings and the measurement of norepinephrine spillover to plasma, there was controversy concerning the state of SNS function in human obesity. These novel techniques applied to obese subjects with normal BP documented that the sympathetic outflow was increased to the kidneys and skeletal muscle vasculature, while it was normal to skin and the hepatomesenteric circulation and reduced to the heart [23-26]. This regional heterogeneity of SNS activation in obese normotensives is mitigated in hypertensives where a more homogenous activation of the SNS has been reported with absence of the suppression of cardiac sympathetic outflow [25-27]. Finally, the distribution of the adipose tissue seems to be crucial for the activation of the SNS since the central pattern of obesity with excess of visceral fat is accompanied by increased MSNA in contrast to men with peripheral obesity where MSNA is no higher than in lean men $[23,28,29]$.

Several mechanisms have been proposed to explain the SNS activation in obese subjects; increased leptin concentration, hyperinsulinemia, OSA, decreased arterial baroreflex sensitivity, elevated plasma angiotensin, obesity-related kidney disease and lack of exercise [23]. Findings of increased MSNA after infusion of insulin in humans could suggest a triggering role of insulin for the SNS [30]. On the other hand, the same procedure in lean hypertensives does not seem to activate the renal sympathetic nerves [31]. Given that obesity is accompanied by increased renal sympathetic activity, mechanisms other than hyperinsulinemia should be considered, taking into account that insulin resistance might be an epiphenomenon of SNS activation. Furthermore, signals arising in adipose tissue that activate the brain have 
been ascribed to adipokines such as leptin. The effects of leptin on the SNS are thought to be mainly driven by binding to leptin receptors in the hypothalamus [32]. Crosssectional studies have shown positive correlations between leptin concentration and various indices of sympathetic activation [33-35]. However, the results of intervention studies examining the effects of leptin infusion on sympathetic activity status are controversial [36-38]. Additionally to these centrally driven effects, nonneural effects of leptin on the cardiovascular system mediated through receptors in the heart and endothelium are supported by the independent association between circulating leptin and heart rate in denervated hearts of transplanted patients [39]. Finally, evidence supports a bidirectional relationship between the renin-angiotensin system and SNS. The stimulation of renin release from juxtaglomerular granular cells through renal sympathetic nerves is well documented [40], while angiotensin facilitates adrenergic function at the level of central and peripheral nervous system [41, 42]. Grassi et al. reported substantial sympathetic inhibition by angiotensin receptor blockade in obesity-related hypertension [43] which is not produced in lean men with or without HTN $[44,45]$.

4.2. Obstructive Sleep Apnea. OSA and HTN are strongly associated, since OSA is an independent predictor for the presence and future development of HTN $[46,47]$. The Wisconsin Sleep Cohort study, a prospective study of the association between sleep-disordered breathing and HTN in 709 subjects, reported a dose-response association between sleep-disordered breathing at baseline and the presence of HTN four-years later that was independent of known confounding factors [48]. This association is particularly strong in patients with $\mathrm{RH}$. In a series of 41 resistant hypertensives, the prevalence of OSA, diagnosed by overnight polysomnographic study, was $83 \%$ and both the prevalence and the severity were significantly higher in men than in women [19]. In case-control studies, OSA was strongly and independently associated with $\mathrm{RH}$ and the apnoeic patients had 4- to 4.8 -fold increased risk of having RH $[49,50]$.

Increased levels of norepinephrine, endothelin and aldosterone, vascular stiffening, activation of the reninangiotensin system, endothelial dysfunction, oxidative stress and SNS hyperactivity have been suggested as explanations for sleep apnea-induced HTN [50-52]. According to the classic systematic review of Coy et al. all studies using MSNA revealed a relationship between sleep apnea and an increase in MSNA. Of the 21 catecholamine papers reviewed, only four failed to report a relationship between OSA and levels of either norepinephrine or epinephrine [53]. Assessment of MSNA has shown a sustained increase in sympathetic output which is increased even during the daytime and in the presence of normoxic wakefulness [54]. Furthermore, sympathetic traffic to peripheral blood vessels was higher in OSA subjects compared to controls with no difference between normotensives and hypertensives [55]. The independent activation of the SNS in apnoeics, regardless of comorbidities, is also documented in obesity. Sympathetic activity in lean men with OSA was elevated to a similar degree as in obese men without OSA, but less than in those with both OSA and obesity, in whom the two conditions exerted an additive effect [56]. Patients with OSA also have faster heart rates during resting wakefulness, suggesting an increased cardiac sympathetic outflow [57]. Further evidence of SNS activation by OSA is provided by studies reporting a reduction in SNS activity after continuous positive airway pressure (CPAP) therapy. In the study of Narkiewicz et al. the decrease of MSNA was evident after both 6 months and 1 year of CPAP therapy [58]. In another study, the decrease in sympathetic activity, estimated by peroneal microneurography at least 1 month after CPAP treatment, was limited to the patients with greater compliance with this device ( $>4.5$ hours/night) [59]. On the other hand, when adrenergic activity was estimated by norepinephrine kinetics and the CPAP treatment was delivered for 14 days, the reduction in plasma levels of norepinephrine was attributed to increased norepinephrine clearance [60].

There seems to be a causal relationship between OSA and SNS activation, despite the lack of established mechanisms by which nocturnal upper airway obstructions leads to daytime sympathetic activation. Both the arousals from sleep and transient hypoxemia, the two major characteristics of OSA syndrome, have been proposed as a linkage between OSA and SNS hyperactivity. However, it is not clear if arousals can influence daytime adrenergic status independently from respiratory disturbances during sleep [61]. When daytime plasma norepinephrine levels were used as an index of daytime sympathetic tone, there was a correlation with movement, but not cortical arousals [62]. On the contrary, the data supporting cyclic intermittent hypoxaemia as the stimulus to SNS activation are more robust. The efferent sympathetic outflow is influenced by peripheral reflex activity, via chemoreceptors and baroreceptors, as well as by central sympathetic activity. Peripheral arterial chemoreceptors have a significant physiological activity in normoxia, the so-called "resting drive". Interestingly, administration of $100 \%$ oxygen, leading to chemoreflex deactivation, is accompanied by a decrease in both MSNA and BP in patients with OSA but not in nonapnoeic control subjects [63]. Thus, elevated MSNA in patients with OSA might be explained in part by tonic activation of excitatory chemoreflex afferents. Molecules such as endothelin and angiotensin II with a stimulating effect on chemosensitivity have been implicated in the mechanisms by which OSA results in increased chemoresponsivness through cyclic intermittent hypoxaemia [64]. Findings of increased expression of the endothelin receptor A and of preproendothelin, and also of upregulation of transcriptional and post-transcriptional expression of angiotensin type 1 receptors, in the carotid body after hypoxia, suggest that these molecules may influence sympathetic activity by modulating peripheral chemoreflex sensitivity after exposure to cyclic intermittent hypoxaemia [64, 65]. Furthermore, evidence support that these molecules can serve as neuromodulators of sympathetic activity in the central nervous system [64]. 
4.3. Excess of Aldosterone. A growing body of evidence suggests that aldosterone contributes broadly to the development and severity of HTN separately from the presence of classically defined primary aldosteronism. The ongoing Framingham Offspring study showed that serum aldosterone levels in normotensive subjects predicted the development of incident HTN and that the patients in the highest serum aldosterone quartile, relative to the lowest had a 1.6-fold risk of HTN during a four-year follow-up [66]. Moreover, a positive correlation was documented between plasma aldosterone and 24-hour ambulatory BP in cross sectional studies $[67,68]$. Among untreated patients, the prevalence of primary aldosteronism increases with the stage of HTN (according to the JNC VI), from $2 \%$ in patients with stage 1 HTN to $8 \%$ in those with stage $2 \mathrm{HTN}$ and $13 \%$ in those with stage 3 HTN [69]. The prevalence of primary aldosteronism is even higher in patients with $\mathrm{RH}$, approaching $17-22 \%$ in multiple studies [70-72]. Furthermore, individuals with true $\mathrm{RH}$ but without primary hyperaldosteronism have higher aldosterone levels than control participants [73]. These findings suggest that aldosterone excess commonly underlies resistance to antihypertensive treatment.

The classic effects of aldosterone are exerted on the renal handling of sodium and potassium leading to expansion of intravascular volume and hypokalemia. In addition, aldosterone promotes $\mathrm{RH}$ by mediating maladaptive changes in the renal, cardiovascular and central nervous systems $[74,75]$. SNS activation seems to be a basic component of the adverse impact of aldosterone excess in the central nervous system. In a cross-over study, sustained SNS stimulation was identified during chlorthalidone administration to hypertensives but not during spironolactone [76]. A recent doubleblind, randomized study by Wray et al. reported a significant reduction in SNS activity after six months of therapy with an aldosterone receptor blocker, which was achieved without a change in end organ a-adrenergic responsiveness, implicating a central mechanism for the change in autonomic activity [77]. The above data extend earlier work in animal models demonstrating the ability of aldosterone receptor blockade to decrease SNS activity in hypertensive mouse models [78].

The mechanisms of aldosterone mediated central SNS activation are becoming clearer. The mineralocorticoid receptor is expressed in many cell types, including specific neurons. Mineralocorticoid receptors in the paraventricular nuclei are involved in the augmented neuronal activity in the nuclei leading to increased sympathetic drive [79]. Multiple studies in animal models are intensively investigating potential pathophysiological pathways. Indicatively, data arising from rats with heart failure demonstrate that mineralocorticoid receptor blockade reduces nicotinaminase adenine dinucleotide phosphate (NADPH) induced superoxide in the paraventicular nuclei of the hypothalamus and reduces descending sympathetic paraventricular nuclei output [80].

\section{Clinical Applications}

Although the clinical investigation has increased our knowledge about the function of the SNS and its involvement in the pathophysiology of several cardiovascular diseases including HTN, there is no current recommendation for the estimation of adrenergic activity in resistant hypertensives. Despite the methodological achievements in the assessment of adrenergic function, reflected in microneurographic measurement of MSNA and measurement of organ specific noradrenaline spillover, no technique can be viewed as the "gold standard" [81], and the above techniques are mainly used for investigational purposes. Regarding the most clinically applicable methods of hemodynamic parameters and noradrenaline measurement in urine and plasma, their limitations should be mentioned. Resting heart rate and heart rate responses to stimuli are regulated not only by the SNS but also by the parasympathetic nervous system and they are also depended on cardiac adrenergic receptors [81]. Furthermore, supine heart rate displays only a limited correlation with other indices of sympathetic activity, as plasma norepinephrine and sympathetic nerve traffic [82]. Concerning 24 hour urinary excretion of catecholamines, the inability of dynamic assessment of the SNS activity, the weakness to determine the systematic or renal origin of catecholamines and the dependence on renal function should be underlined [83]. As regards plasma noradrenaline levels, low reproducibility, low sensitivity and biological restrictions to discriminate between increased secretion or reduced clearance of elevated circulating neurotransmitter constitute substantial limitations $[81,84]$.

The therapeutic strategy in $\mathrm{RH}$ aims to block all possible mechanisms for BP elevation. Combination therapy with appropriate diuretic selection and dosing remains the cornerstone of treatment. According to the 2007 ESC/ESH guidelines for the management of arterial hypertension, patients with $\mathrm{RH}$ will need administration of more than three drugs [85]. Studies suggest that adding spironolactone or eplerenone to existing antihypertensive regimens for patients with $\mathrm{RH}$ provides significant BP reduction $[11,85,86]$. Most importantly, reductions in BP were similar in patients with and without primary aldosteronism and were not predicted by baseline plasma or 24 hour urinary aldosterone, plasma renin activity or plasma aldosterone to renin ratio [87]. With the usual therapeutic options the SNS hyperactivity is blocked to the peripheral level of adrenergic receptors with the use of alpha and beta blockers and it should be mentioned once more that rising data suggest a sympathoinhibitory effect of angiotensin and mineralocorticoid receptor blocking [43, 76, 77]. Centrally acting agents are effective antihypertensive agents but have a high incidence of adverse effects and lack outcome data [11]. Finally, promising results arrive from recent studies of interventional methods of sympathoinhibition including activation of the carotid baroreceptors using electrical stimuli [88] and selective renal sympathetic denervation [89].

\section{Conclusions}

Obesity, OSA, and aldosterone excess are common comorbidities in resistant hypertensives. Screening of these underlying conditions in patients with $\mathrm{RH}$ is of major clinical 
importance. SNS hyperactivity is a common characteristic of all the above conditions supporting its crucial role in the pathophysiology of antihypertensive treatment resistance. The further investigation and understanding of the mechanisms leading to SNS activation could reveal novel therapeutic targets and expand our treatment options in the challenging management of RH.

\section{References}

[1] S. Oparil, M. A. Zaman, and D. A. Calhoun, "Pathogenesis of hypertension," Annals of Internal Medicine, vol. 139, no. 9, pp. 761-776, 2003.

[2] World Health Organization, World Health Report 2002: Reducing Risks, Promoting Healthy Life, World Health Organization, Geneva, Switzerland, 2002.

[3] P. A. Sarafidis and G. L. Bakris, "Resistant hypertension: an overview of evaluation and treatment," Journal of the American College of Cardiology, vol. 52, no. 22, pp. 1749-1757, 2008.

[4] G. Grassi, "Assessment of sympathetic cardiovascular drive in human hypertension: achievements and perspectives," Hypertension, vol. 54, no. 4, pp. 690-697, 2009.

[5] G. Grassi, G. Seravalle, G. Bertinieri et al., "Sympathetic and reflex alterations in systo-diastolic and systolic hypertension of the elderly," Journal of Hypertension, vol. 18, no. 5, pp. 587$593,2000$.

[6] G. Grassi, G. Seravalle, F. Q. Trevano et al., "Neurogenic abnormalities in masked hypertension," Hypertension, vol. 50, no. 3, pp. 537-542, 2007.

[7] G. Grassi, G. Seravalle, F. Quarti-Trevano et al., "Adrenergic, metabolic, and reflex abnormalities in reverse and extreme dipper hypertensives," Hypertension, vol. 52, no. 5, pp. 925931,2008

[8] H. P. Schobel, T. Fischer, K. Heuszer, H. Geiger, and R. E. Schmieder, "Preeclampsia-a state of sympathetic overactivity," The New England Journal of Medicine, vol. 335, no. 20, pp. 1480-1485, 1996.

[9] E. A. Anderson, C. A. Sinkey, W. J. Lawton, and A. L. Mark, "Elevated sympathetic nerve activity in borderline hypertensive humans. Evidence from direct intraneural recordings," Hypertension, vol. 14, no. 2, pp. 177-183, 1989.

[10] G. Grassi, B. M. Cattaneo, G. Seravalle, A. Lanfranchi, and G. Mancia, "Baroreflex control of sympathetic nerve activity in essential and secondary hypertension," Hypertension, vol. 31, no. 1, pp. 68-72, 1998.

[11] D. A. Calhoun, D. Jones, S. Textor et al., "Resistant hypertension: siagnosis, evaluation, and treatment a scientific statement from the american heart association professional education committee of the council for high blood pressure research," Hypertension, vol. 51, no. 6, pp. 1403-1419, 2008.

[12] M. J. Joyner, N. Charkoudian, and B. G. Wallin, "Sympathetic nervous system and blood pressure in humans: individualized patterns of regulation and their implications," Hypertension, vol. 56, no. 1, pp. 10-16, 2010.

[13] E. C. Hart, M. J. Joyner, B. G. Wallin et al., "Age-related differences in the sympathetic-hemodynamic balance in men," Hypertension, vol. 54, no. 1, pp. 127-133, 2009.

[14] P. P. Jones, L. F. Shapiro, G. A. Keisling et al., "Altered autonomic support of arterial blood pressure with age in healthy men," Circulation, vol. 104, no. 20, pp. 2424-2429, 2001.

[15] J. Fagius and B. G. Wallin, "Long-term variability and reproducibility of resting human muscle nerve sympathetic activity at rest, as reassessed after a decade," Clinical Autonomic Research, vol. 3, no. 3, pp. 201-205, 1993.

[16] G. Sundlof and B. G. Wallin, "Human muscle nerve sympathetic activity at rest. Relationship to blood pressure and age," Journal of Physiology, vol. 274, pp. 621-637, 1978.

[17] K. Narkiewicz, B. G. Phillips, M. Kato, D. Hering, L. Bieniaszewski, and V. K. Somers, "Gender-selective interaction between aging, blood pressure, and sympathetic nerve activity," Hypertension, vol. 45, no. 4, pp. 522-525, 2005.

[18] D. A. Calhoun, M. K. Nishizaka, M. A. Zaman, R. B. Thakkar, and P. Weissmann, "Hyperaldosteronism among black and white subjects with resistant hypertension," Hypertension, vol. 40, no. 6, pp. 892-896, 2002.

[19] A. G. Logan, S. M. Perlikowski, A. Mente et al., "High prevalence of unrecognized sleep apnoea in drug-resistant hypertension," Journal of Hypertension, vol. 19, no. 12, pp. 2271-2277, 2001.

[20] D. A. Calhoun, M. K. Nishizaka, M. A. Zaman, and S. M. Harding, "Aldosterone excretion among subjects with resistant hypertension and symptoms of sleep apnea," Chest, vol. 125, no. 1, pp. 112-117, 2004.

[21] D. M. Lloyd-Jones, J. C. Evans, M. G. Larson, C. J. O’Donnell, E. J. Roccella, and D. Levy, "Differential control of systolic and diastolic blood pressure factors associated with lack of blood pressure control in the community," Hypertension, vol. 36, no. 4, pp. 594-599, 2000.

[22] P. Bramlage, D. Pittrow, H. U. Wittchen et al., "Hypertension in overweight and obese primary care patients is highly prevalent and poorly controlled," American Journal of Hypertension, vol. 17, no. 10, pp. 904-910, 2004.

[23] M. Esler, N. Straznicky, N. Eikelis, K. Masuo, G. Lambert, and E. Lambert, "Mechanisms of sympathetic activation in obesity-related hypertension," Hypertension, vol. 48, no. 5, pp. 787-796, 2006.

[24] M. Vaz, G. Jennings, A. Turner, H. Cox, G. Lambert, and M. Esler, "Regional sympathetic nervous activity and oxygen consumption in obese normotensive human subjects," Circulation, vol. 96, no. 10, pp. 3423-3429, 1997.

[25] G. Grassi, M. Colombo, G. Seravalle, D. Spaziani, and G. Mancia, "Dissociation between muscle and skin sympathetic nerve activity in essential hypertension, obesity, and congestive heart failure," Hypertension, vol. 31, no. 1, pp. 64-67, 1998.

[26] G. Grassi, G. Seravalle, B. M. Cattaneo et al., "Sympathetic activation in obese normotensive subjects," Hypertension, vol. 25, no. 4, pp. 560-563, 1995.

[27] M. S. Rumantir, M. Vaz, G. L. Jennings et al., "Neural mechanisms in human obesity-related hypertension," Journal of Hypertension, vol. 17, no. 8, pp. 1125-1133, 1999.

[28] G. E. Alvarez, S. D. Beske, T. P. Ballard, and K. P. Davy, "Sympathetic neural activation in visceral obesity," Circulation, vol. 106, no. 20, pp. 2533-2536, 2002.

[29] G. E. Alvarez, T. P. Ballard, S. D. Beske, and K. P. Davy, "Subcutaneous obesity is not associated with sympathetic neural activation," American Journal of Physiology, vol. 287, no. 1, pp. H414-H418, 2004.

[30] P. Vollenweider, L. Tappy, D. Randin et al., "Differential effects of hyperinsulinemia and carbohydrate metabolism on sympathetic nerve activity and muscle blood flow in humans," The Journal of Clinical Investigation, vol. 92, no. 1, pp. 147-154, 1993.

[31] S. Gudbjornsdottir, P. Friberg, M. Elam, S. Attvall, P. Lonnroth, and B. G. Wallin, "The effect of metformin and insulin on sympathetic nerve activity, norepinephrine spillover and blood pressure in obese, insulin resistant, normoglycemic, 
hypertensive men," Blood Pressure, vol. 3, no. 6, pp. 394-403, 1994.

[32] K. Rahmouni and D. A. Morgan, "Hypothalamic arcuate nucleus mediates the sympathetic and arterial pressure responses to leptin," Hypertension, vol. 49, no. 3, pp. 647-652, 2007.

[33] M. T. Guagnano, M. R. Manigrasso, E. Ballone et al., "Association between serum leptin levels and 24-hour blood pressure in obese women," Obesity Research, vol. 11, no. 4, pp. 549-555, 2003.

[34] G. Paolisso, D. Manzella, N. Montano, A. Gambardella, and M. Varricchio, "Plasma leptin concentrations and cardiac autonomic nervous system in healthy subjects with different body weights," The Journal of Clinical Endocrinology \& Metabolism, vol. 85, no. 5, pp. 1810-1814, 2000.

[35] N. Eikelis, M. Schlaich, A. Aggarwal, D. Kaye, and M. Esler, "Interactions between leptin and the human sympathetic nervous system," Hypertension, vol. 41, no. 5, pp. 1072-1079, 2003.

[36] M. Rosenbaum, R. Goldsmith, D. Bloomfield et al., "Lowdose leptin reverses skeletal muscle, autonomic, and neuroendocrine adaptations to maintenance of reduced weight," The Journal of Clinical Investigation, vol. 115, no. 12, pp. 35793586, 2005.

[37] R. M. Mackintosh and J. Hirsch, "The effects of leptin administration in non-obese human subjects," Obesity Research, vol. 9, no. 8, pp. 462-469, 2001.

[38] J. L. Chan, J. E. Mietus, P. M. Raciti, A. L. Goldberger, and C. S. Mantzoros, "Short-term fasting-induced autonomic activation and changes in catecholamine levels are not mediated by changes in leptin levels in healthy humans," Clinical Endocrinology, vol. 66, no. 1, pp. 49-57, 2007.

[39] M. Winnicki, B. G. Phillips, V. Accurso et al., "Independent association between plasma leptin levels and heart rate in heart transplant recipients," Circulation, vol. 104, no. 4, pp. 384-386, 2001.

[40] G. F. DiBona, "Nervous kidney: interaction between renal sympathetic nerves and the renin-angiotensin system in the control of renal function," Hypertension, vol. 36, no. 6, pp. 1083-1088, 2000.

[41] C. M. Ferrario, P. L. Gildenberg, and J. W. McCubbin, "Cardiovascular effects of angiotensin mediated by the central nervous system," Circulation Research, vol. 30, no. 3, pp. 257262, 1972.

[42] B. G. Zimmerman, E. J. Sybertz, and P. C. Wong, "Interaction between sympathetic and renin-angiotensin system," Journal of Hypertension, vol. 2, no. 6, pp. 581-587, 1984.

[43] G. Grassi, G. Seravalle, R. Dell'Oro et al., "Comparative effects of candesartan and hydrochlorothiazide on blood pressure, insulin sensitivity, and sympathetic drive in obese hypertensive individuals: results of the CROSS study," Journal of Hypertension, vol. 21, no. 9, pp. 1761-1769, 2003.

[44] H. Krum, E. Lambert, E. Windebank, D. J. Campbell, and M. Esler, "Effect of angiotensin II receptor blockade on autonomic nervous system function in patients with essential hypertension," American Journal of Physiology, vol. 290, no. 4, pp. H1706-H1712, 2006.

[45] K. Heusser, J. Vitkovsky, W. Raasch, R. F. Schmieder, and H. P. Schobel, "Elevation of sympathetic activity by eprosartan in young male subjects," American Journal of Hypertension, vol. 16, no. 8, pp. 658-664, 2003.

[46] C. Tsioufis, C. Thomopoulos, and C. Stefanadis, "Obstructive sleep apnoea and hypertension: a growing clinical challenge,"
Hellenic Journal of Cardiology, vol. 49, no. 5, pp. 299-302, 2008.

[47] C. Tsioufis, A. Kasiakogias, C. Thomopoulos, A. Manolis, and C. Stefanadis, "Managing hypertension in obstructive sleep apnea: the interplay of continuous positive airway pressure, medication and chronotherapy," Journal of Hypertension, vol. 28, no. 5, pp. 875-882, 2010.

[48] S. C. Gonçalves, D. Martinez, M. Gus et al., "Obstructive sleep apnea and resistant hypertension: a case-control study," Chest, vol. 132, no. 6, pp. 1858-1862, 2007.

[49] P. Ruttanaumpawan, C. Nopmaneejumruslers, A. G. Logan, A. Lazarescu, I. Qian, and T. D. Bradley, "Association between refractory hypertension and obstructive sleep apnea," Journal of Hypertension, vol. 27, no. 7, pp. 1439-1445, 2009.

[50] T. L. Goodfriend and D. A. Calhoun, "Resistant hypertension, obesity, sleep apnea, and aldosterone: theory and therapy," Hypertension, vol. 43, no. 3, pp. 518-524, 2004.

[51] C. Thomopoulos, C. Tsioufis, K. Dimitriadis et al., "Obstructive sleep apnoea syndrome is associated with enhanced sub-clinical inflammation and asymmetric dimethyl-arginine levels in hypertensives," Journal of Human Hypertension, vol. 23, no. 1, pp. 65-67, 2009.

[52] C. Tsioufis, K. Thomopoulos, K. Dimitriadis et al., "The incremental effect of obstructive sleep apnoea syndrome on arterial stiffness in newly diagnosed essential hypertensive subjects," Journal of Hypertension, vol. 25, no. 1, pp. 141-146, 2007.

[53] T. V. Coy, J. E. Dimsdale, S. Ancoli-Israel, and J. Clausen, "Sleep apnoea and sympathetic nervous system activity: a review," Journal of Sleep Research, vol. 5, no. 1, pp. 42-50, 1996.

[54] V. K. Somers, M. E. Dyken, M. P. Clary, and F. M. Abboud, "Sympathetic neural mechanisms in obstructive sleep apnea," The Journal of Clinical Investigation, vol. 96, no. 4, pp. 18971904, 1995.

[55] J. T. Carlson, J. Hedner, M. Elam, H. Ejnell, J. Sellgren, and B. G. Wallin, "Augmented resting sympathetic activity in awake patients with obstructive sleep apnea," Chest, vol. 103, no. 6, pp. 1763-1768, 1993.

[56] G. Grassi, A. Facchini, F. Q. Trevano et al., "Obstructive sleep apnea-dependent and -independent adrenergic activation in obesity," Hypertension, vol. 46, no. 2, pp. 321-325, 2005.

[57] K. Narkiewicz, N. Montano, C. Cogliati, P. J. H. van de Borne, M. E. Dyken, and V. K. Somers, "Altered cardiovascular variability in obstructive sleep apnea," Circulation, vol. 98, no. 11, pp. 1071-1077, 1998.

[58] K. Narkiewicz, M. Kato, B. G. Phillips, C. A. Pesek, D. E. Davison, and V. K. Somers, "Nocturnal continuous positive airway pressure decreases daytime sympathetic traffic in obstructive sleep apnea," Circulation, vol. 100, no. 23, pp. 2332-2335, 1999.

[59] N. V. Waradekar, L. I. Sinoway, C. W. Zwillich, and U. A. Leuenberger, "Influence of treatment on muscle sympathetic nerve activity in sleep apnea," American Journal of Respiratory and Critical Care Medicine, vol. 153, no. 4, pp. 1333-1338, 1996.

[60] P. J. Mills, B. P. Kennedy, J. S. Loredo, J. E. Dimsdale, and M. G. Ziegler, "Effects of nasal continuous positive airway pressure and oxygen supplementation on norepinephrine kinetics and cardiovascular responses in obstructive sleep apnea," Journal of Applied Physiology, vol. 100, no. 1, pp. 343-348, 2006.

[61] M. Hornyak, M. Cejnar, M. Elam, M. Matousek, and B. G. Wallin, "Sympathetic muscle nerve activity during sleep in man," Brain, vol. 114, no. 3, pp. 1281-1295, 1991. 
[62] J. S. Loredo, M. G. Ziegler, S. Ancoli-Israel, J. L. Clausen, and J. E. Dimsdale, "Relationship of arousals from sleep to sympathetic nervous system activity and BP in obstructive sleep apnea," Chest, vol. 116, no. 3, pp. 655-659, 1999.

[63] K. Narkiewicz, P. J. H. van de Borne, N. Montano, M. E. Dyken, B. G. Phillips, and V. K. Somers, "Contribution of tonic chemoreflex activation to sympathetic activity and blood pressure in patients with obstructive sleep apnea," Circulation, vol. 97, no. 10, pp. 943-945, 1998.

[64] J. W. Weiss, M. D. Y. Liu, and J. Huang, "Physiological basis for a causal relationship of obstructive sleep apnoea to hypertension," Experimental Physiology, vol. 92, no. 1, pp. 2126, 2007.

[65] S. Y. Lam, M. L. Fung, and P. S. Leung, "Regulation of the angiotensin-converting enzyme activity by a time-course hypoxia in the carotid body," Journal of Applied Physiology, vol. 96, no. 2, pp. 809-813, 2004.

[66] R. S. Vasan, J. C. Evans, M. G. Larson et al., "Serum aldosterone and the incidence of hypertension in nonhypertensive persons," The New England Journal of Medicine, vol. 351, no. 1, pp. 33-111, 2004.

[67] A. H. El-Gharbawy, V. S. Nadig, J. M. Kotchen et al., "Arterial pressure, left ventricular mass, and aldosterone in essential hypertension," Hypertension, vol. 37, no. 3, pp. 845-850, 2001.

[68] C. E. Grim, A. W. Cowley, P. Hamet et al., "Hyperaldosteronism and hypertension ethnic differences," Hypertension, vol. 45, no. 4, pp. 766-772, 2005.

[69] L. Mosso, C. Carvajal, A. González et al., "Primary aldosteronism and hypertensive disease," Hypertension, vol. 42, no. 2, pp. 161-165, 2003.

[70] B. J. Gallay, S. Ahmad, L. Xu, B. Toivola, and R. C. Davidson, "Screening for primary aldosteronism without discontinuing hypertensive medications: plasma aldosterone-renin ratio," American Journal of Kidney Diseases, vol. 37, no. 4, pp. 699$705,2001$.

[71] I. K. Eide, P. A. Torjesen, A. Drolsum, A. Babovic, and N. P. Lilledahl, "Low-renin status in therapy-resistant hypertension: a clue to efficient treatment," Journal of Hypertension, vol. 22, no. 11, pp. 2217-2226, 2004.

[72] B. Štrauch, T. Zelinka, M. Hampf, R. Bernhardt, and J. Widimsky Jr., "Prevalence of primary hyperaldosteronism in moderate to severe hypertension in the Central Europe region," Journal of Human Hypertension, vol. 17, no. 5, pp. 349-352, 2003.

[73] K. K. Gaddam, M. K. Nishizaka, M. N. Pratt-Ubunama et al., "Characterization of resistant hypertension: association between resistant hypertension, aldosterone, and persistent intravascular volume expansion," Archives of Internal Medicine, vol. 168, no. 11, pp. 1159-1164, 2008.

[74] J. R. Sowers, A. Whaley-Connell, and M. Epstein, "Narrative review: the emerging clinical implications of the role of aldosterone in the metabolic syndrome and resistant hypertension," Annals of Internal Medicine, vol. 150, no. 11, pp. 776-783, 2009.

[75] C. Tsioufis, D. Tsiachris, K. Dimitriadis et al., "Myocardial and aortic stiffening in the early course of primary aldosteronism," Clinical Cardiology, vol. 31, no. 9, pp. 431-436, 2008.

[76] D. V. Menon, D. Arbique, Z. Wang, B. Adams-Huet, R. J. Auchus, and W. Vongpatanasin, "Differential effects of chlorthalidone versus spironolactone on muscle sympathetic nerve activity in hypertensive patients," The Journal of Clinical Endocrinology \& Metabolism, vol. 94, no. 4, pp. 1361-1366, 2009.
[77] D. W. Wray and M. A. Supiano, "Impact of aldosterone receptor blockade compared with thiazide therapy on sympathetic nervous system function in geriatric hypertension," Hypertension, vol. 55, no. 5, pp. 1217-1223, 2010.

[78] K. Rahmouni, M. Barthelmebs, M. Grima, J. L. Imbs, and W. De Jong, "Involvement of brain mineralocorticoid receptor in salt-enhanced hypertension in spontaneously hypertensive rats," Hypertension, vol. 38, no. 4, pp. 902-906, 2001.

[79] E. P. Gomez-Sanchez, "Central mineralocorticoid receptors and cardiovascular disease," Neuroendocrinology, vol. 90, no. 3, pp. 245-250, 2009.

[80] Y. Yu, S. G. Wei, Z. H. Zhang, E. Gomez-Sanchez, R. M. Weiss, and R. B. Felder, "Does aldosterone upregulate the brain renin-angiotensin system in rats with heart failure?" Hypertension, vol. 51, no. 3, pp. 727-733, 2008.

[81] G. Grassi and M. Esler, "How to assess sympathetic activity in humans," Journal of Hypertension, vol. 17, no. 6, pp. 719-734, 1999.

[82] G. Grassi, S. Vailati, G. Bertinieri et al., "Heart rate as marker of sympathetic activity," Journal of Hypertension, vol. 16, no. 11, pp. 1635-1639, 1998.

[83] I. J. Kopin, "Catecholamine metabolism: basic aspects and clinical significance," Pharmacological Reviews, vol. 37, no. 4, pp. 333-364, 1985.

[84] G. Grassi, G. Bolla, G. Seravalle, C. Turri, A. Lanfranchi, and G. Mancia, "Comparison between reproducibility and sensitivity of muscle sympathetic nerve traffic and plasma noradrenaline in man," Clinical Science, vol. 92, no. 3, pp. 285289, 1997.

[85] G. Mancia, G. De Backer, A. Dominiczak et al., “2007 Guidelines for the management of arterial hypertension: the Task Force for the Management of Arterial Hypertension of the European Society of Hypertension (ESH) and of the European Society of Cardiology (ESC)," European Heart Journal, vol. 28, no. 12, pp. 1462-1536, 2007.

[86] F. Zannad, "Aldosterone antagonist therapy in resistant hypertension," Journal of Hypertension, vol. 25, no. 4, pp. 747-750, 2007.

[87] M. K. Nishizaka, M. A. Zaman, and D. A. Calhoun, "Efficacy of low-dose spironolactone in subjects with resistant hypertension," American Journal of Hypertension, vol. 16, no. 11, pp. 925-930, 2003.

[88] I. J. M. Scheffers, A. A. Kroon, J. Schmidli et al., "Novel baroreflex activation therapy in resistant hypertension: results of a European multi-center feasibility study," Journal of the American College of Cardiology, vol. 56, no. 15, pp. 1254-1258, 2010.

[89] H. Krum, M. Schlaich, R. Whitbourn et al., "Catheter-based renal sympathetic denervation for resistant hypertension: a multicentre safety and proof-of-principle cohort study," The Lancet, vol. 373, no. 9671, pp. 1275-1281, 2009. 


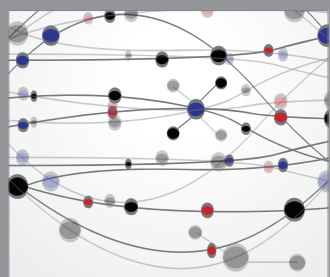

The Scientific World Journal
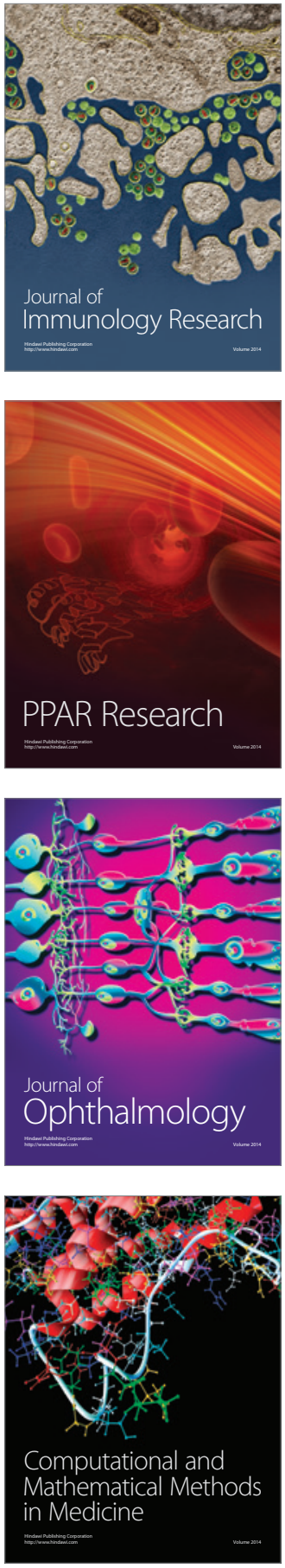

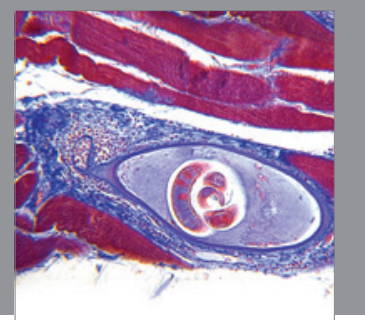

Gastroenterology

Research and Practice
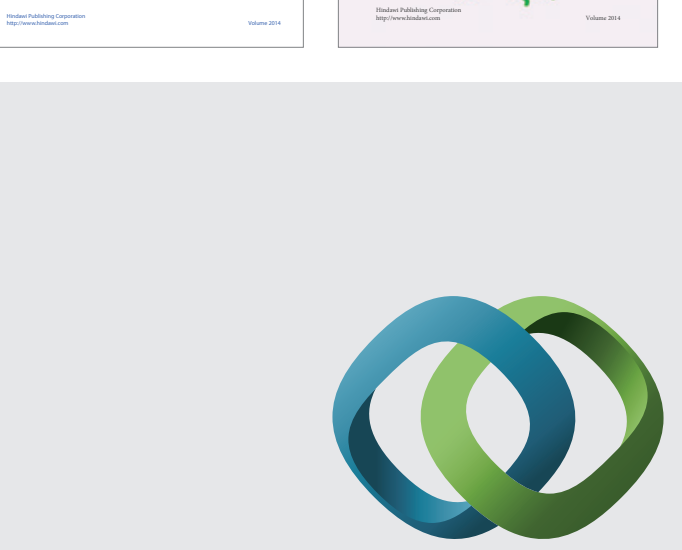

\section{Hindawi}

Submit your manuscripts at

http://www.hindawi.com
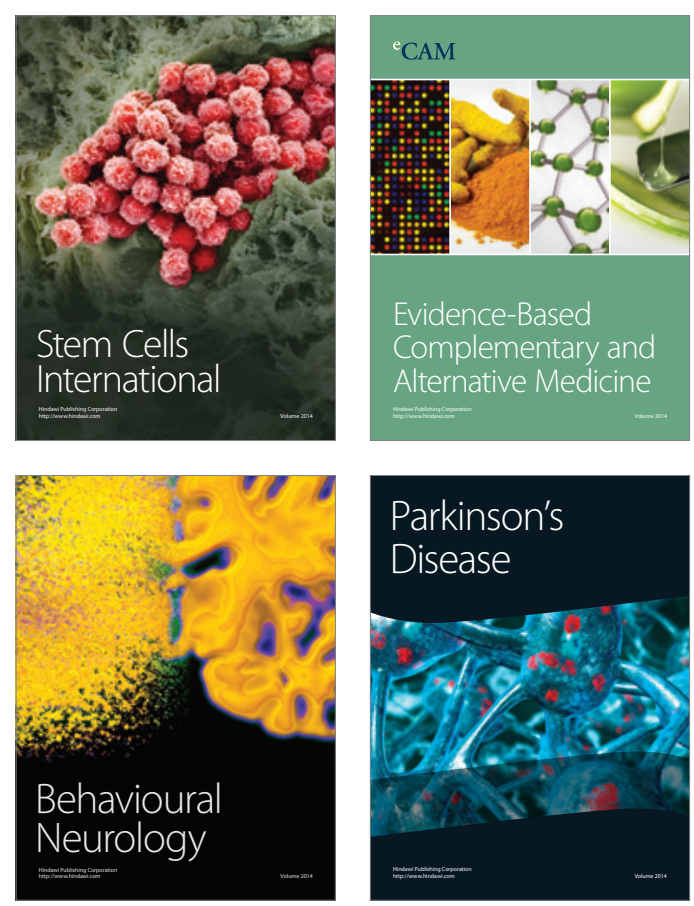

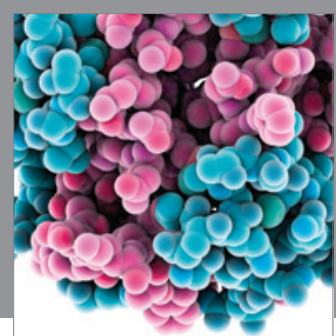

Journal of
Diabetes Research

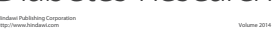

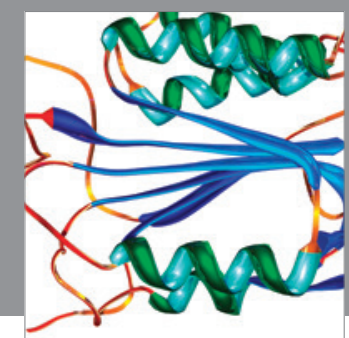

Disease Markers
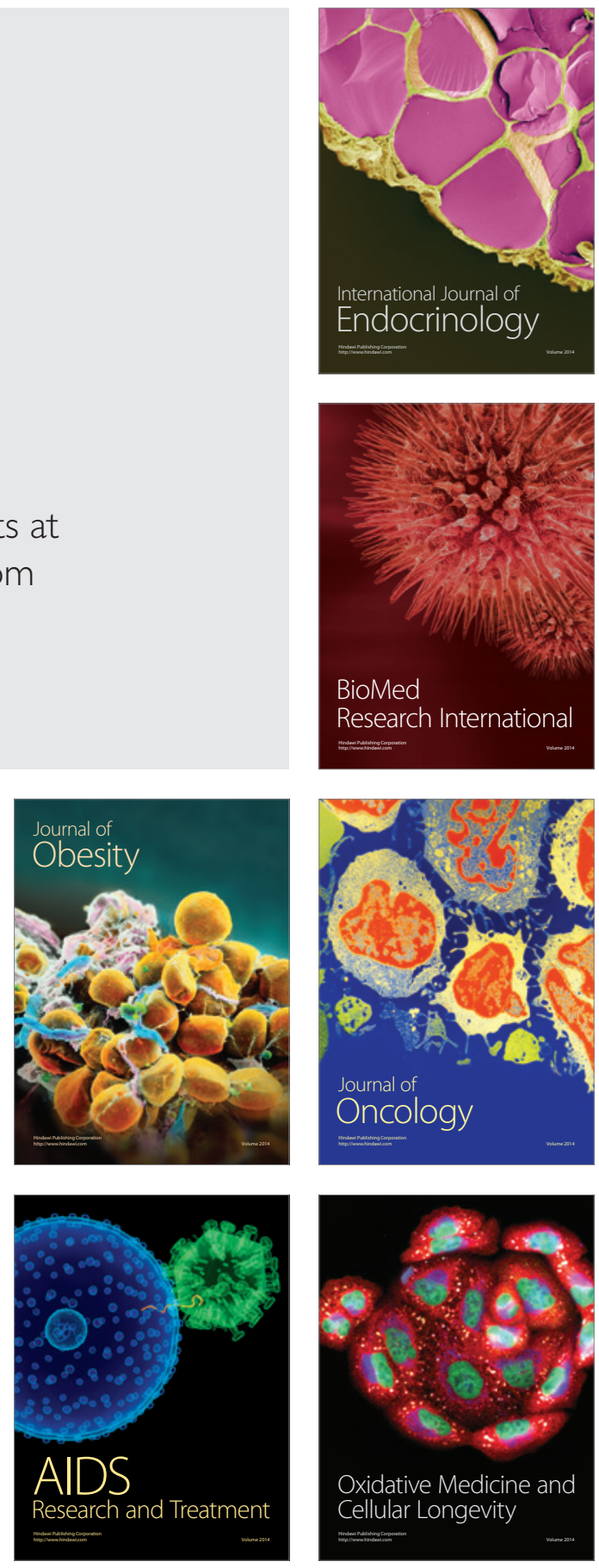